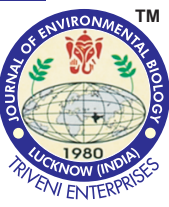

\title{
Landuse impact on soil physical variability and erodibility in North Western subtropics of India
}

\begin{tabular}{lll}
\hline Paper received: 23.07.2018 & Revised received: 06.01.2019 Re-revised received: $30.01 .2019 \quad$ Accepted: 26.03.2019 \\
\hline
\end{tabular}

\section{Authors Info \\ V. Abrol ${ }^{1 *}$, R.K. Sharma', V. Sharma', P. Sharma', K.R. Sharma ${ }^{2}$, A. Kumar and M. Sharma ${ }^{3}$ \\ ${ }^{1}$ Advanced Centre for Rainfed Agriculture, Sher-e-Kashmir University of Agricultural Sciences \& Technology, Jammu-181 133, India \\ ${ }^{2}$ Division of Soil Science \& Agri-Chemistry, Faculty of Agriculture, Sher-e-Kashmir University of Agricultural Sciences \& Technology, Jammu-180 009, India \\ ${ }^{3}$ Division of Statistics and Computer Science, Faculty of Basic Sciences, Sher-e-Kashmir University of Agricultural Sciences \& Technology, Jammu-180 009, India \\ *Corresponding Author Email : abrolvics@gmail.com}

\section{Edited by \\ Dr. R.B. Raizada}

Reviewed by

Dr. Vivak M. Arya

Dr. Ram Marathe

\section{Abstract}

Aim : The study was conducted to determine the impact of landuse on soil physical properties and erodibility.

Methodology : Representative soil samples were collected from surface and sub-surface soil depths. Soil physical properties and erodibility indices viz suspension percentage, dispersion ratio, clay/moisture equivalent ratio, erosion ratio, percolation ratio, clay ratio, erosion index and modified clay ratio were determined using standard procedures. Interrelationship among soil properties and erodibility indices were evaluated using Pearson correlation analysis (at 95\% and 99\% significance level).

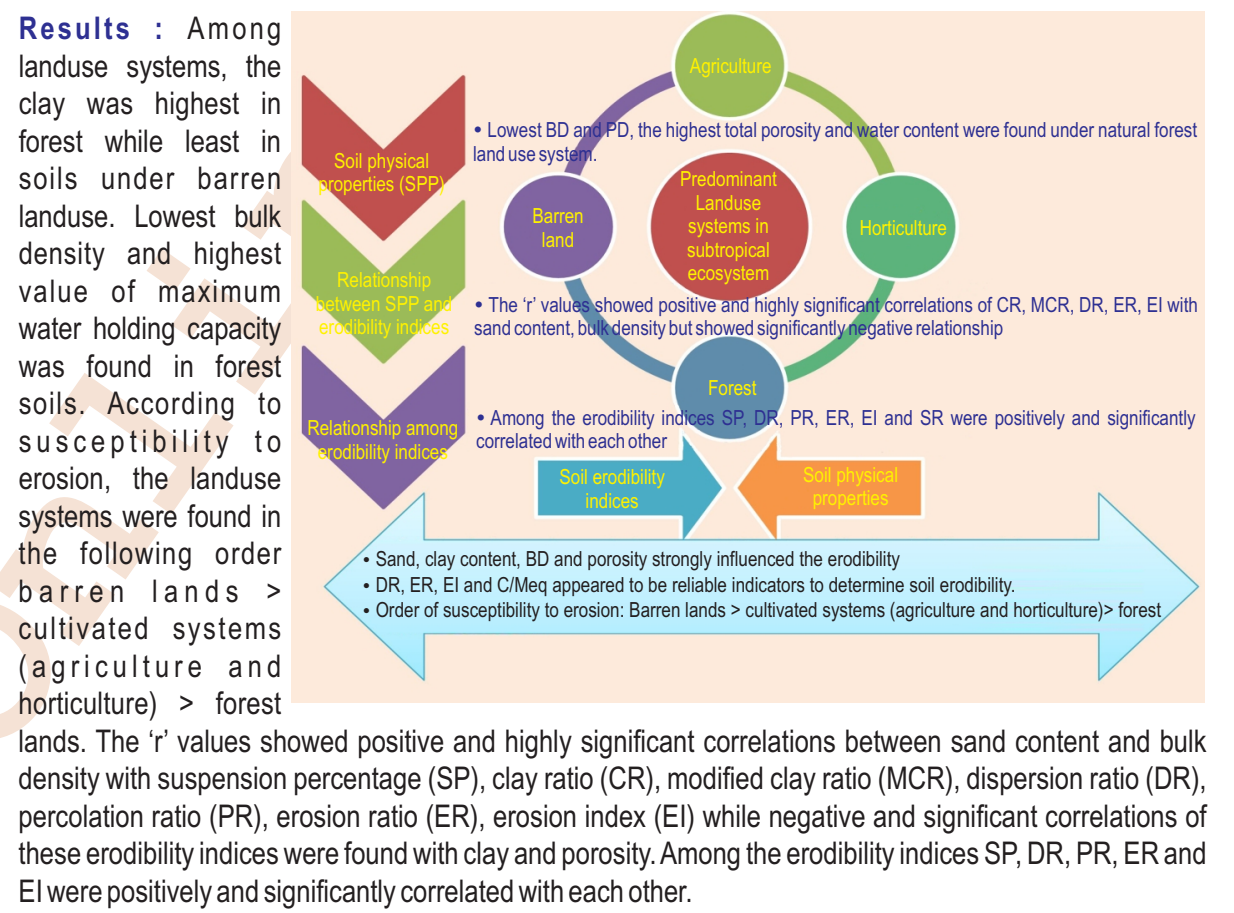

Interpretation : Physical quality of soil was higher in forest compared to other landuse systems. Erodibility of different landuse systems could be arranged in order barren lands $>$ cultivated systems (agriculture and horticulture) $>$ forests. The study was useful for suggesting remedial measures and landuse planning for future.

Key words: Erodibility indices, Landuse systems, Soil physical properties, Subtropical ecosystem

How to cite : Abrol, V., R.K. Sharma, V. Sharma, P. Sharma, K.R. Sharma, A. Kumar and M. Sharma: Landuse impact on soil physical variability and erodibility in North Western subtropics of India. J. Environ. Biol., 40, 668-673 (2019). 


\section{Introduction}

The accelerated soil erosion is among the most pressing of environmental problems, resulting in degradation of ecosystem function, decreased productivity and sustainability of agriculture and displacement of human populations (Ludwig et al., 2006 Diamond, 2005; Ludwig and Tongway, 2000; Opie, 2000). As human demands increase, the sustainable use of land becomes imperative. The over exploitation of natural resources by human has resulted in forced landuse changes and destruction of forests and rangelands to obtain farmlands, is still a significant problem in many countries around the world (Korkanc et al., 2008). The Himalayan eco-system sustaining over 150 million people is in peri with ecological disasters. Anthropogenic pressure leading to denudation of forests at an alarming rate, overgrazing of pastures, construction of roads and big hydro-electric projects, unscientific mining, agriculture and horticulture activities without any due considerations to soil conservations measures in hills are further aggravating the menace of soil erosion, resulting into accelerated erosion of top soil layer leading the degradation of the land.

The problem is more acute in Shiwaliks comprising northwestern foothills of the Himalayas in the states of Jammu and Kashmir, Punjab, Himachal Pradesh, Haryana, and Uttar Pradesh. The Shiwaliks are comprised of sandstone, grit and conglomerates with characters of fluvial deposits with deep soils, but slopes near the foothills contain pebbles and boulders. These formations are geologically weak and unstable (Singh et al., 1992). The foothills of Shiwaliks, covering an area of $2.14 \times 10^{6}$ ha, is a sub-mountainous region of Northwestern Himalayas that suffers from soil erosion due to uneven topography, high soil erodibility and erosivity of rains (Arora et al., 2006). Even in clay loam soil in the region with a slope of 2 to 3 per cent, there is loss of upto 106.5 tonnes ha ${ }^{-1}$ year ${ }^{-1}$ (Gupta, 2005). In Jammu region, the damage to soil because of water erosion is considerable, especially in the tracts lying under outer or Shiwalik Himalayas, most of which occur during south-west monsoon season.

The extent and severity of erosion is a function of the intensity of rainfall, land slope, soil characteristics and land use. Meanwhile, top-soil physical and chemical properties, i.e. soil texture (Liu et al., 2017), bulk density (Wang et al., 2017) and organic matter content are also greatly affected by land use (Wang et al., 2013b). A thorough understanding of soil physical parameters is essential for assessment of soil erosion and productivity for planning effective soil and water conservation programmes in the area. The suitability of soil for different land uses traditionally has been expressed as a function of soil texture (Wischmeier et al., 1971). Konkarc et al., (2008) found that according to land use types, soil erodibility was related to soil texture (clay fraction). Soil erodibility reflects the soil's susceptibility to erosion, and it is a key parameter for predicting soil loss and assessing the benefits of soil conservation practices (Wang et al., 2013a). Soils with high erodibility need more intensive conservation practices than those with low erodibility. Also with increasing population pressure on agricultural land, it may become necessary in near future to cultivate marginal lands that are highly erodible. Soils under different landuse systems, therefore, pose a serious soil erosion hazard of varied degree, thereby depleting the soil fertility, eventually resulting into low crop yield. The study was aimed to determine the impact of different landuse systems on soil physical properties, soil erodibility and to determine relationship between erodibility indices and soil properties.

\section{Materials and Methods}

Location of study area: The Jammu region lies between $32^{\circ} 17^{\prime}$ $34^{\circ} 11^{\prime} \mathrm{N}$ latitudes and $73^{\circ} 35^{\prime}-76^{\circ} 46^{\prime} \mathrm{E}$ longitudes and agroclimatically, the region is broadly classified into low altitude subtropical, intermediate and temperate zones having an elevation upto $800 \mathrm{~m}, 800-1500 \mathrm{~m}$ and above $1500 \mathrm{~m}$, respectively and the study area comprises subtropical zone. Forest, agriculture, horticulture and barren lands are major landuse patterns in Jammu.

Characteristics of subtropical ecosystem: Low altitude subtropical zone is characterized by monsoonal rainfall and hot summer. May and June are the hottest months during which temperature rises to $45^{\circ} \mathrm{C}$ whereas December and January are the coldest months. The mean annual rainfall and temperature is $1115 \mathrm{~mm}$ and $29^{\circ} \mathrm{C}$. The mean maximum and minimum temperatures range between $39.9^{\circ} \mathrm{C}$ and $23.4^{\circ} \mathrm{C}$ in summer and $26.3^{\circ} \mathrm{C}$ and $6.5^{\circ} \mathrm{C}$ in winter. The mean summer temperature and mean winter temperature are $32^{\circ} \mathrm{C}$ and $8.4^{\circ} \mathrm{C}$. The soils in study area are shallow to deep, well drained, coarse loamy to fine loamy, calcareous as well as non calcareous, severely eroded, low available water capacity (AWC), neutral to slightly alkaline in reaction, medium organic carbon $(\mathrm{OC})$ and composed of sandstone, shales, conglomerates and clay beds.

Soil sample collection and processing: On the basis of reconnaissance survey, topographic variations and area under different landuse classes, stratified random sampling technique was followed for the selection of sampling sites. Accordingly, representative sites were exposed upto $0.45 \mathrm{~m}$ depth under different land uses. A total of 96 representative soil samples were collected from two depths i.e. $0-0.22$ and $0.22-0.45 \mathrm{~m}$ for laboratory analysis. After collection, soil samples were air dried, grounded in a wooden pestle, passed through $2 \mathrm{~mm}$ sieve and used for analysis. Particle size analysis was done by International Pipette Method, bulk density, particle density and pore space were determined as outlined by Chopra and Kanwar (1991), water holding capacity was determined by Keen Raczkowski Box method (Chopra and Kanwar, 1991), moisture equivalent was determined by Brigg's and McLane Centrifuge method (Piper, 1966), organic carbon by Walkley and Black's rapid titration method (Piper, 1966), Dispersion ratio was determined by dividing undispersed (silt+clay) percentage to dispersed (silt+clay) percentage (Middleton, 1930), colloid-moisture equivalent ratio was determined by dividing clay percentage to moisture capacity of the soil samples (Baver, 1956), Erosion ratio 
was determined by dividing dispersion ratio to colloid- moisture equivalent ratio (Balci, 1996), Clay Ratio (CR) by dividing (\% sand $+\%$ silt) to $\%$ clay, Modified Clay Ratio (MCR) by dividing (\% sand $+\%$ silt) to (\% clay + $\%$ organic matter) (Bouyoucos, 1935), Percolation ratio as the possible index of susceptibility was determined as ratio of suspension percentage and clay / moisture equivalent ratio Slater and Byers (1931), Suspension percentage was determined as percentage of silt + clay in an undispersed sample of soil (Middleton, 1930) and Erosion index was calculated dividing dispersion ratio to ratio of clay to half of water holding capacity (Sahi et al.,1977). Data were evaluated by Pearson correlation analysis (at 95\% and 99\% significance level).

\section{Results and Discussion}

The results revealed that the amount of clay content decreased in order of forest $>$ horticulture $>$ agriculture $>$ barren landuse system (Table 1). Barren land had the highest sand content and least in the soils of forest due to dwarf roots of grasses in low depths. High clay content in forest soil compared to other landuse has been reported by Agnihotri et al. (2007). Irrespective of soil depth, the bulk density of surface soil was generally lower than sub surface soil which could be ascribed to greater compaction that might have occurred in the lower layers of soil with time. Barren land evinced higher values of bulk density than those of other landuse systems and the lowest bulk density was found in forest soil (Fig. 1 a). These findings are further supported by low clay and high sand content (Table 1) and low organic carbon, highly erodible nature of the soils under barren lands. Highly significant and negative correlation was observed in bulk density of clay and organic carbon $\left(r=-0.512^{* *}\right.$ and $\left.0.536^{* *}\right)$ and $\left(r=-0.531^{* *}\right.$ and $\left.-0.639^{* *}\right)$ in surface and subsurface soils, respectively, further strengthens these results. Gupta et al. (2010) also reported a negative correlation between bulk density with organic carbon and clay content in eroded forest soils of outer Himalayas. Among the landuse systems, the average values of particle density were in the order: forest lands < agriculture < horticulture < barren landuse (Fig. 1 a). The particle density in all the profile samples increased with depth, which may be due to lower soil organic carbon concentrations in lower layers and higher amount of heavier coarse sand fractions. A negative correlation of particle density with organic carbon and clay content indicates that with the decrease of organic carbon and finer fraction of soil (clay), the value of particle density would increase. Blanco-Canqui et al. (2006) ascribed increase in organic carbon as soil solid could lower the soil particle density.

Among different landuse systems, the porosity showed increasing trend in order of forest $>$ agriculture $>$ horticulture $>$ barren lands with $22 \%, 13 \%$ and $12 \%$ increase in surface soil depth, respectively over the barren landuse system whereas the percent increase in MWHC was $22.1 \%, 13.3 \%$ and $12.4 \%$ in forest, agriculture and horticulture landuse respectively over the barren landuse in surface soil depth (Fig. 1 b). The highest values of water holding capacity and porosity in forest soils may be due to high organic matter content, low bulk density, high amount of finer fractions which is attributed to their higher surface area. This is supported by a positive significant correlation of water holding capacity with organic carbon and clay content. Higher water holding capacity was likely caused by the increase in soil porosity, especially macropores, resulted from the accumulation of the incorporated plant litter and the development of root systems within top-soil layer (Wang and Zhang, 2017) and Gol (2009) postulated that each one percent of organic matter adds about 1.5 percent to water holding capacity.

Taking 15 and 10 as threshold level of DR and ER respectively, the soils were found to be highly erodible under all land uses (Fig 2). DR was ordered as barren land > agriculture > horticulture $>$ forest whereas the erosional behaviour with respect to ER was found in order of: barren land > horticulture > agriculture > forest. Similarly, Li et al. (2015) found that soil erodibility was grearer in cropland than in forest. ER of barren land was 3.3 and 3.2 times higher compared with forest landuse system followed by horticulture (1.6 and 1.6 times), agriculture (1.4 and 1.3 times) in surface and sub-surface soils, respectively. It could be due to addition of leaf biomass under forestry in the surface layers (Sun et al., 2016). Both forest and cultivated lands had comparatively lower El and might be subjected to lesser degree of erosion. However, considering 2.8, threshold value of $\mathrm{El}$, all soils qualified for erodible class and need conservation measures on priority to prevent their further degradation. Different

Table 1 : Soil textural variation in surface and sub-surface soil influenced by different landuse systems

\begin{tabular}{|c|c|c|c|c|c|}
\hline \multirow[t]{2}{*}{ Landuse system } & \multirow[t]{2}{*}{ Soil depth $(\mathrm{cm})$} & \multirow[t]{2}{*}{ Clay } & Silt & Sand & \multirow[t]{2}{*}{ Textural class } \\
\hline & & & $\%$ & & \\
\hline \multirow[t]{2}{*}{ Forest } & $0-22$ & 28.7 & 20.03 & 51.24 & sandy clay loam \\
\hline & $22-45$ & 28.3 & 25.74 & 45.96 & sandy clay loam \\
\hline \multirow[t]{2}{*}{ Agriculture } & $0-22$ & 24.57 & 23.52 & 51.95 & sandy clay loam \\
\hline & $22-45$ & 23.44 & 24.34 & 52.22 & sandy clay loam \\
\hline \multirow[t]{2}{*}{ Horticulture } & $0-22$ & 26.52 & 15.22 & 58.26 & sandy clay loam \\
\hline & $22-45$ & 24.06 & 21.64 & 54.29 & sandy clay loam \\
\hline \multirow[t]{2}{*}{ Barren land } & $0-22$ & 15.37 & 16.91 & 67.72 & sandy loam \\
\hline & $22-45$ & 14.24 & 16.77 & 68.99 & sandy loam \\
\hline
\end{tabular}




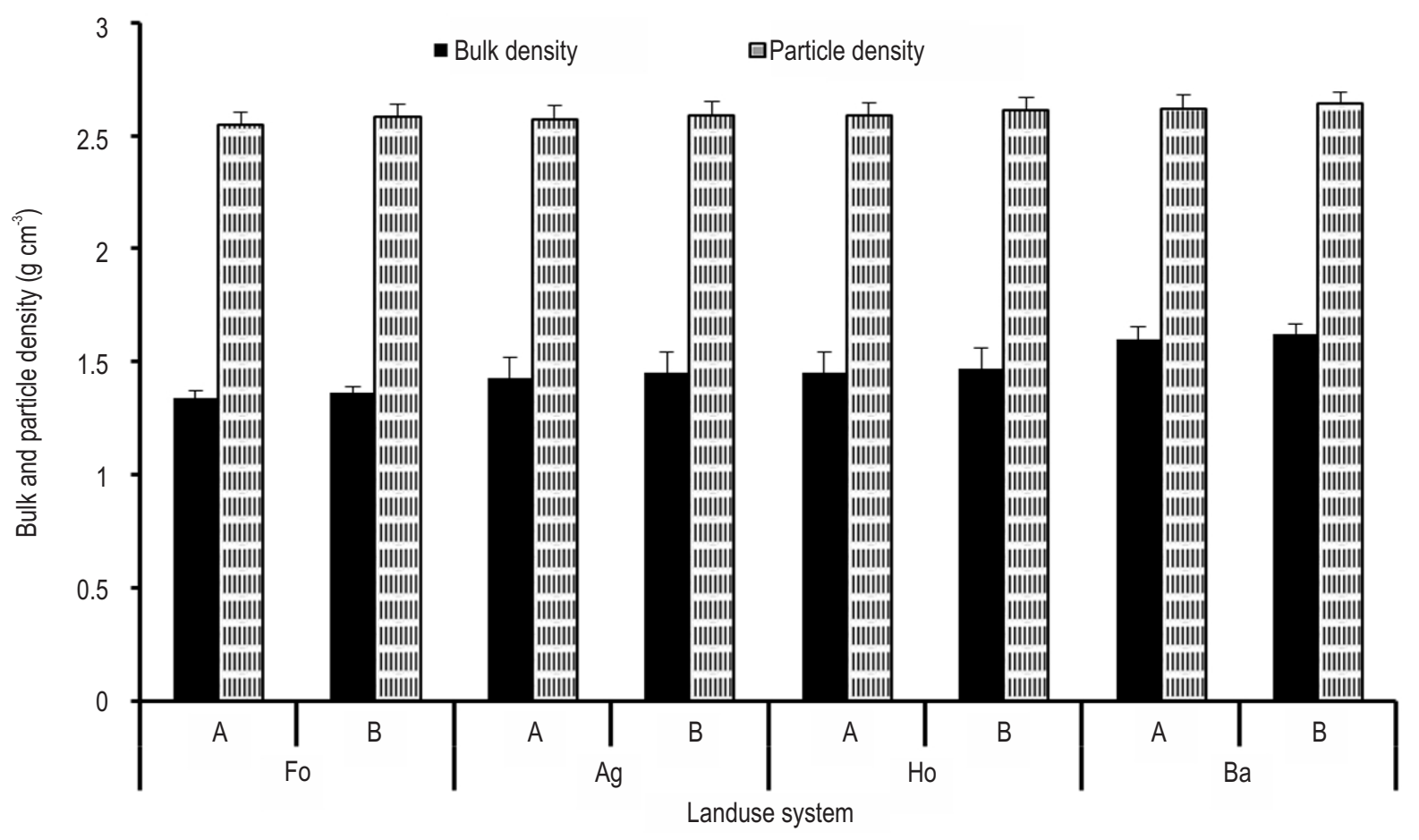

Fig 1 (a) : Impact of different landuse systems in surface and subsurface soil depth on bulk and particle density.

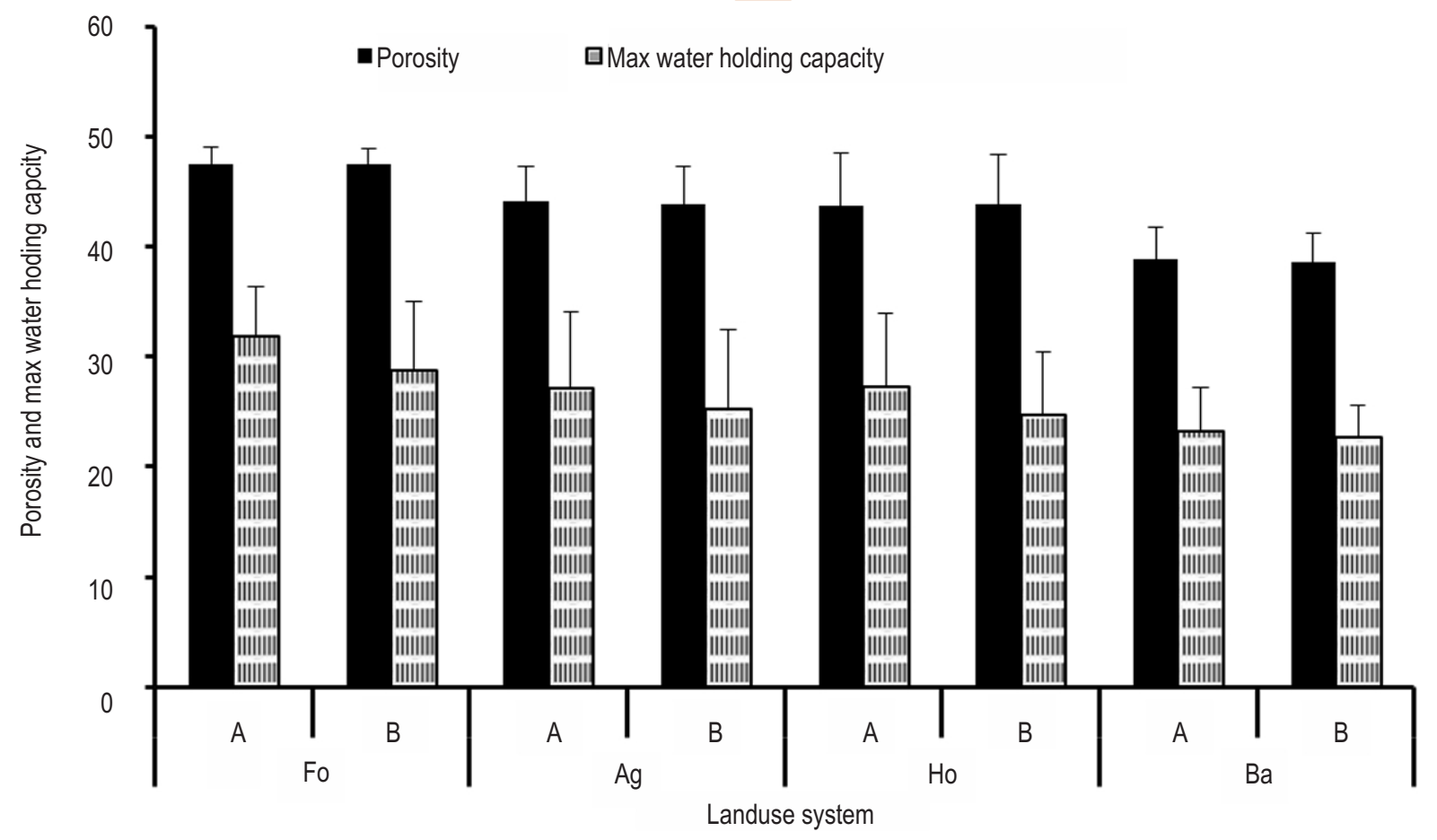

Fig 1 (b) : Impact of different landuse systems in surface and subsurface soil depth on porosity and maximum water holding capacity. 


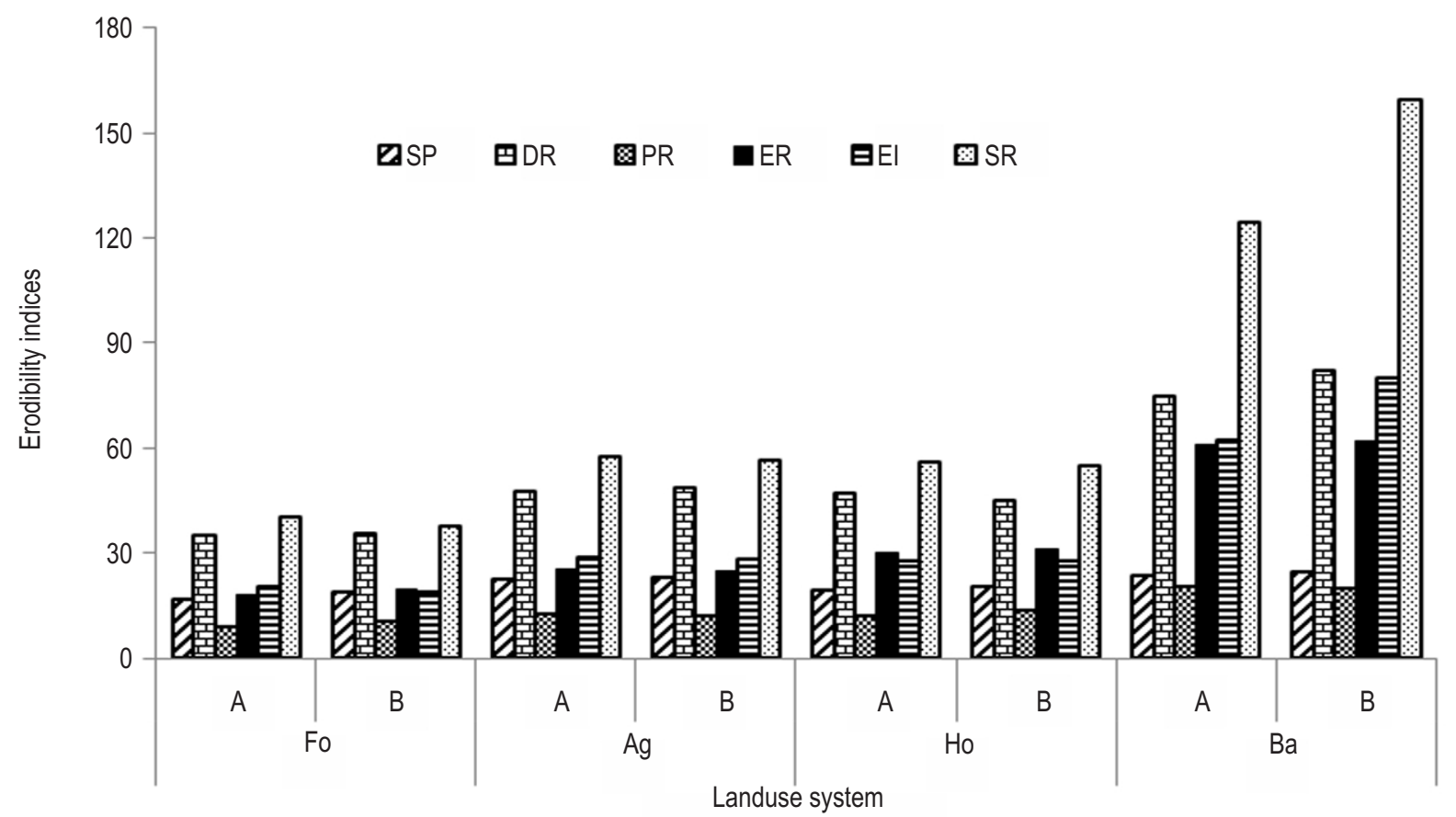

Fig. 2 : Erodibility indices in surface and subsurface soil depth under different landuse systems.

landuses for erosional behaviour as per El could be arranged in the order of barren land $>$ horticulture $>$ agriculture $>$ forest. Likewise, SR and PR were found 3.10 and 2.25 times, 1.41 and 1.59 times, 1.40 and 1.45 times higher in barren landuse in relation to forest, agriculture and horticulture, respectively in surface soil. The higher vegetative cover, higher clay content and organic matter in forest may be ascribed to least susceptibility of forest landuse to erosion with respect to DR, $E R, S R$ and El whereas continuous tillage operations in agriculture might contribute to higher erosion than horticulture landuse. The results are corroborated by significantly negative correlation of clay with DR $\left(r=-0.363^{*}\right.$ and $\left.-0.341^{*}\right)$, ER $(r=$ $0.290^{*}$ and -0.222$)$, El $\left(r=-0.680^{* *}\right.$ and $\left.-0.705^{* *}\right)$ and sand percent $\left(r=-0.662^{* *}\right.$ and $\left.-0.777^{* *}\right)$ in both soil depths. Singh et al. (2012) also reported that clay, silt and organic carbon were significantly and negatively correlated with erosion ratio. The conditions in forest land use were beneficial to the accumulation of plant litter in near soil surface layer as compared to arable soils and also surface layers under agriculture become loose by continuous tillage operations Li et al. (2015).

Among the erodibility indices, ER had highly significant and positive correlation with $\mathrm{DR}\left(r=0.930^{* *}\right.$ and $\left.0.920^{* *}\right), \mathrm{PR}(\mathrm{r}=$ $0.861^{* *}$ and $\left.0.824^{* *}\right)$ and $\mathrm{SP}\left(r=0.761^{* *}\right.$ and $\left.0.752^{* *}\right)$ in surface and subsurface soil depth substantiating the earlier findings (Kumar et al., 2017). Erodibility indices DR, ER, El and CR and MCR were consistent in reliance upon soil physical properties $B D$, sand, clay and porosity and evinced highly significant positive correlation with $\mathrm{BD}\left(r=0.526^{* *}, r=0.477^{* *}, r=0.505^{\star *}, r=0.563^{* *}\right.$ and $\left.r=0.576^{* *}\right)$ and sand $\left(r=0.313^{* *}, r=0.208, r=0.437^{* *}, r=\right.$ $0.670^{* *}$ and $r=0.682^{* *}$ ), respectively, in surface soils. The highly significant negative correlation was found between DR, ER, El, CR and MCR with clay and porosity $\left(r=-0.363^{*}\right.$ and $\left.-0.463^{* *}\right),(r=$ $-0.290^{*}$ and $\left.-0.420^{*}\right),\left(r=-0.680^{* *}\right.$ and $\left.-0.402^{* *}\right),\left(r=-0.894^{* *}\right.$ and $\left.-0.473^{* *}\right)$ and $\left(r=-0.905^{* *}\right.$ and $\left.-0.482^{* *}\right)$ respectively in surface soils substantiating the earlier findings of Karagul (1999). Similar trend was observed in subsurface soils.

The higher ' $r$ ' values between ER, DR, and El among erodibility indices and with soils properties suggested that these indices could be used to study erodibility behaviour of soils. However, C/Meq generally evinced significant and negative relationship with various with $\mathrm{DR}, \mathrm{ER}, \mathrm{PR}$ and $\mathrm{SP}$ erodibility indices. The results suggested that $D R$ and $E R$ as better indicators than other indices to determine soil erodibility due to higher degree of colinearity and consistent results. Khera and Kalhon (2005) concluded that both ER and DR are equally good indices of soil erodibility. CR and MCR also showed higher degree of colinearity due to same numerator and addition of organic carbon in denominator in case of MCR. Similar had been findings of Kusre et al. (2018). The study concludes that croplands landuse are most sensitive to erosion and preventive measures against erosion must be taken to aggrade soil resilience. Soil texture, clay content, BD and porosity emerges as potential indicators for evaluating 
erodibility of the soil. The study is useful for deciding landuse planning, keeping in mind the sensitivity of study area to erosion.

\section{Acknowledgments}

First author is highly indebted to supporting staff of Division of Soil Science and Agri-Chemistry, Faculty of Agriculture, SKUAST-Jammu especially laboratory technician for providing logistics and rendering necessary support during the pursuing of laboratory analysis.

\section{References}

Agnihotri, R.C., R.C. Yadav and P. Jha: Erodibility characteristics of entisol soils of riparian zone of the Yamuna river in Agra: Impacts of land form and land uses. Indian. J. Soil. Cons., 35, 226-229 (2007).

Arora, S.: Preliminary assessment of soil and water conservation status in drought prone foothill region of north-west India. J. World. Assoc. Soil. Water. Cons., 1, 55-63 (2006)

Balci, A.N.: Soil Conservation. I.U. Forestry Faculty Publication Number: 439, Istanbul University Press, Istanbul (1996).

Baver. L.D.: Soil physics. $3^{\text {rd }}$ Edn., John Wiley and Sons, Inc., New York, p. $489(1956)$

Blanco-Canqui, H., R. Lal, W.M. Post, R.C. Izaurralde and M.J. Shiptalo: Organic carbon influences on soil particle density and rheological properties. Soil Sci. Soc. America. J., 70, 1407-1414 (2006).

Bouyoucos, G.J.: The clay ratio as a criterion of susceptibility of soils to erosion. J. American. Soc. Agronomy., 27, 738-741 (1935).

Chopra, S.L. and J.S. Kanwar: Analytical Agricultural Chemistry. Kalyani Publishers, New Delhi-Ludhiana (1991).

Diamond, J.: Collapse: How Societies Choose to Succeed or Fail. Viking Press, New York, p.592 (2005)

Gol, C.: The effect of land use changes on soil properties and organic carbon at Dagdami river catchment in Turkey. J. Environ. Biol., 30 825-830 (2009)

Gupta, G.D., R.D. Gupta, D. Kher and N.M. Sumberia: Studies on soil erodibility indices in relation to soil properties in kandi belt of Jammu district. J. Res. SKAUST-J. 4, 209-213 (2005)

Gupta, R.D., S. Arora, G.D. Gupta and N.M. Sumberia: Soil physical variability in relation to soil erodibility under different land uses in foothills of Siwaliks in N-W India. Tropical Ecology, 51, 183-197 (2010).

Karagül, R.: Investigations on soil erodibility and some properties of soils under different land use types in Ogutludere creek watershed near Trabzon. Tr. J. Agric. For., 23, 53-68 (1999).

Khera, K.L. and M.S. Kahlon. Impact of land use patterns on soil erosion in sub-montane Punjab. J.Ind. Soc. Soil. Sc., 48, 205-206 (2005)

Korkanc, S.Y., N. Ozyuvaci and A. Hizal. Impacts of land use conversion on soil properties and soil erodibility. J. Environ. Bio., 29, 363-370 (2008)

Kumar, K., M. Kumar and A. Kumar. Soil erodibility assessment under various conservation measures at Babina watershed in
Bundelkhand region. Indian. J. Soil. Cons., 45, 89-95 (2017).

Kusre, B. C., P.Ghosh and K. Nath. Prioritization of soil conservation measures using erodibility indices as criteria in Sikkim (India). J. Earth. Sys. Sc., 127, 81 (2018).

Li, Z.W., G.H. Zhang, R. Geng and H. Wang: Land use impacts on soil detachment capacity by overland flow in the Loess Plateau, China. Catena, 124, 9-17 (2015).

Liu, F., G.H. Zhang, F.B. Sun, H. Wang and L. Sun: Quantifying the surface covering, binding and bonding effects of biological soil crusts on soil detachment by overland flow. Earth Surf. Process. Land, 42, 2640-2648 (2017).

Ludwig, J.A. and D.J. Tongway: Viewing rangelands as landscape systems. In: Rangeland Desertification (Eds.: O. Arnalds and S. Archer) Kluwer Academic Publishers, Dordrecht, pp. 39-52 (2000).

Ludwig, J.A., R.W. Eager, A.C. Liedloff, G.N. Bastin and V.H. Chewings: A new landscape leakiness index based on remotely sensed ground-cover data. Ecological Indicators, 6, 327-336 (2006).

Middleton, H.E.: Properties of soils which influence soil erosion. Technical Bulletin, United States Department of Agriculture, Washington, 178, pp. 1-16 (1930)

Opie, J. Ogallala: Water for a Dry Land. University of Nebraska Press, Lincoln, pp. 46-61 (2000).

Piper, C.S.: Soil and PlantAnalysis. Hans Publishers, Bombay (1966).

Sahi, B.P., S.N. Singh, A.C. Sinha and B. Acharya: Erosion index - a new index of soil erodibility. J.Ind. Soc. Soil. Sc., 25, 7-10 (1977).

Singh, G., R. P. Babu, L. Narain, S. Bhushan and I.P. Abrol: Soil erosion rates in India. J. Soil. Water. Cons., 47, 97-99 (1992).

Singh, R. P., P.N. Yadav, A.K. Tripathi, S.K. Uttam and S.C. Katiyar: Relationship of soil properties with erodibility indices in different land use systems in Central alluvial tract of Uttar Pradesh. Curr. Adv. Agril. Sc., 4, 116-120 (2012).

Slater, C.S. and H.B. Byers: United States Department of Agriculture, Technical Bulletin 232. G.C. 1980. Soil erodibility under different land uses. Indian J. Soil. Cons., 8, 101-105(1931).

Sun, L., G.H. Zhang, L.L. Luan and F. Liu: Temporal variation in soil resistance to flowing water erosion for soil incorporated with plant litters in the Loess Plateau of China. Catena, 145, 239-245 (2016).

Wang, B. and G.H. Zhang. Quantifying the binding and bonding effects of plant roots on soil detachment by overland flow in ten typical grasslands on the Loess Plateau. Soil Sci. Soc. Am. J., 81, 15671576 (2017)

Wang, B., F. Zheng, M.J.M. Romkens and F. Darboux: Soil erodibility for water erosion: A perspective and Chinese experiences. Geomorphology, 187, 1-10 (2013a).

Wang, B., G.H. Zhang. Y.Y. Shi, X.C. Zhang, Z.P. Rena and L.J. Zhu: Effect of natural restoration time of abandoned farmland on soil detachment by overland flow in the Loess Plateau of China. Earth Surf. Process Landf., 38, 1725-1734(2013b).

Wang, H., G.H. Zhang, F. Liu, R. Geng and L.J. Wang: Effect of biological crust coverage on soil hydraulic properties for the Loess Plateau of China. Hydrol. Process., 31, 1-11 (2017).

Wischmeier, W.H., C.B. Johnson and B.V. Cross: A soil erodibility nomograph for farmland and construction sites. J. Soil. Water Cons., 26, 189-192(1971). 